\title{
MUCOADHESIVE BUCCAL PATCHES OF LORNOXICAM: I- DEVELOPMENT AND IN-VITRO CHARACTERIZATION
}

\author{
Fawzia Habib, Maha Abdel Azeem, Gihan Fetih and Mohamed Safwat
}

Department of Pharmaceutics, Faculty of Pharmacy, Assiut University, Assiut, Egypt

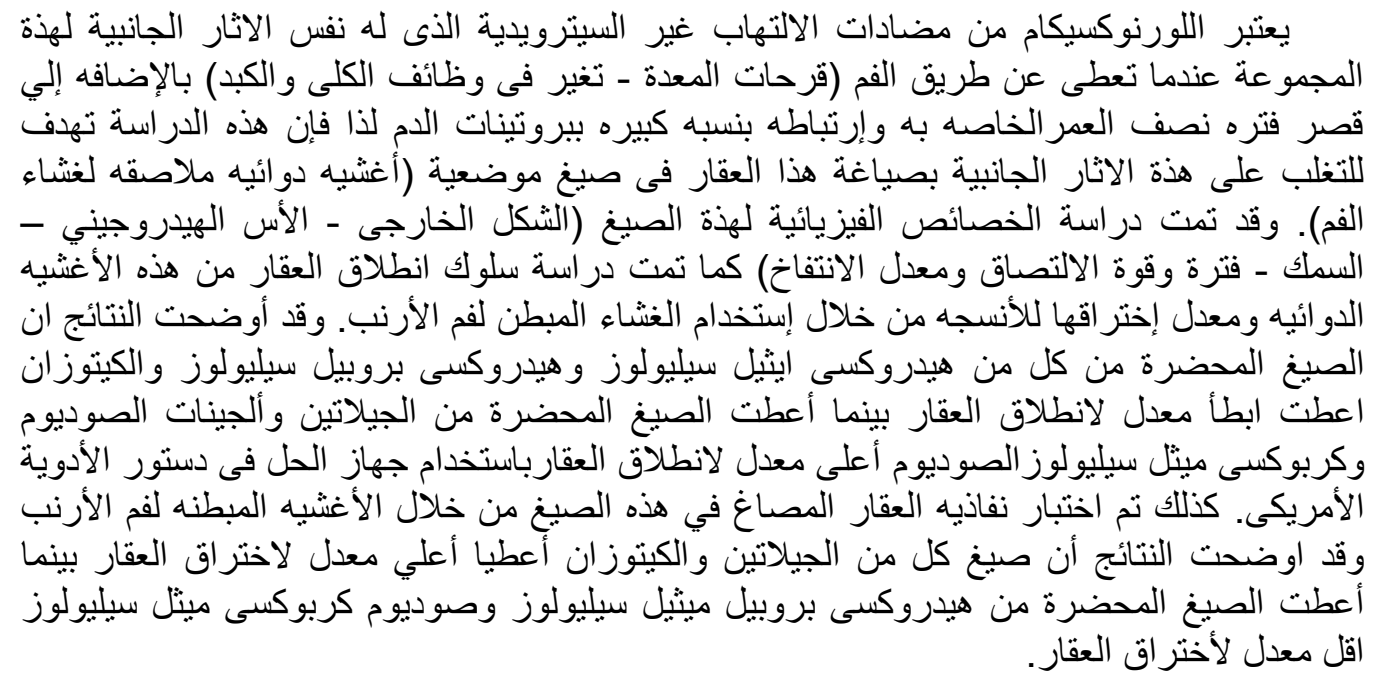

Lornoxicam as a non-steroidal anti-inflammatory drug (NSAID) has the same side effects of this group if taken orally (GIT, renal, and hepatic disorders). Lornoxicam and its metabolites bind extensively to plasma albumin (99\%), beside that, it has a relatively short half-life (3 to 5 hrs). The drug was formulated in mucoadhesive buccal patches using different polymers including, hydroxyethyl cellulose (HEC), hydroxypropyl cellulose (HPC), hydroxypropylmethyl cellulose (HPMC), chitosan, polyvinyl alcohol (PVA), gelatin, sodium alginate and sodium carboxymethyl cellulose (Na CMC).

The physical characteristics of the formulated patches as mass uniformity, patch thickness, surface $\mathrm{pH}$, folding endurance, swelling, residence time as well as mucoadhesion (in-vitro and ex-vivo mucoadhesion force) were evaluated. The in-vitro release of the drug from the formulated patches was studied using the USP dissolution apparatus, and the results indicated that HEC, HPC and chitosan showed the lowest drug release $170 \%, 76 \%$, and $81 \%$, respectively) while gelatin, sodium alginate and $\mathrm{Na} C M C$ gave the highest release (nearly $100 \%$ ). Permeation of lornoxicam formulated in different patches through rabbit buccal mucosa was also studied and the results showed that gelatin and chitosan patches resulted in the highest drug permeation. Kinetics of drug release from the different patches was found to follow zero order or diffusion kinetics.

\section{INTRODUCTION}

Retentive buccal mucoadhesive formulations may be a viable alternative to the conventional oral medications as they can be readily attached to the buccal cavity, retained for a longer period of time and removed at any time. Many attempts have been made to formulate various mucoadhesive delivery systems including tablets, films, patches, disks, strips, ointments, and gels for many drugs. It was reported that buccal patches are highly flexible and thus much more readily tolerated by the patient than tablets ${ }^{1}$. Patches also ensure more accurate dosing of the drug compared to gels and ointments.

Drugs which can be used topically in the mouth include antimicrobials, topical corticosteroids, local anaesthetics, antibiotics, NSAIDs, and anti-dental caries drugs ${ }^{1}$. 
Lornoxicam is a member of the oxicam class of NSAIDs with analgesic, antiinflammatory and antipyretic properties. It is available in oral and parenteral formulations. It is often used for the treatment of inflammatory disease of the joints, osteoarthritis, pain following surgery and pain in the lower back and hip which travels down the back of the thigh into the leg (sciatica). The drug is absorbed rapidly and almost completely from the gastrointestinal tract ${ }^{2}$. Although the usual oral dose of (4-8) $\mathrm{mg}$ of lornoxicam is well tolerated by the patients, yet several side effects have been reported including: stomach pains, nausea, vomiting, dizziness, somnolence, drowsiness, headache and flushing ${ }^{2}$. In addition to the gastrointestinal adverse effects, it binds extensively to plasma albumin (99\%), and has a relatively short plasma half-life (3 to $5 \mathrm{hrs})^{3}$ which makes it a good candidate for local delivery via sustained release dosage forms.

The aim of this study was to formulate lornoxicam in mucoadhesive buccal patches to release the drug in a sustained manner and adequate concentration at the target site and to avoid the side effects of the drug.

The mucoadhesive patches were prepared using cationic and non-ionic polymers in different concentrations and the physical characters of the patches (mass uniformity, patch thickness, surface $\mathrm{pH}$, folding endurance, swelling, residence time, mucoadhesion (invitro and ex-vivo mucoadhesion force) were studied. The in-vitro drug release and permeation through rabbit buccal mucosa were carried out. The kinetics of drug release was also investigated.

\section{EXPERIMENTAL}

\section{Materials}

Lornoxicam was a gift from Chema Pharm, Egypt. Hydroxypropyl cellulose (HPC) was obtained from (T3A Co. Assiut, Egypt). Hydroxypropylmethyl cellulose (HPMC), Hydroxyethyl cellulose (HEC), Poly vinyl alcohol (PVA), Chitosan, and sodium tauroglycholate, (Sigma Aldirch Co., USA). Sodium carboxy methyl cellulose (Na CMC) and sodium alginate (Dow Chemical Co. USA). Propylene glycol and gelatin, (El-Nasr Chemical Co., Cairo, Egypt).

\section{Apparatus}

Magnetic stirrer with hot plate (Gallenkamp, England). UV-Spectrophotometer (Shimadzu-50-02, Kyoto, Japan). Digital pH meter (Genway Ltd., England). Dissolution apparatus (Erweka DT-D6, Duesseldorf, Germany). Electronic digital micrometer 0.25 mm (MIME Technology, Netherlands).

\section{Methods}

\section{Preparation of mucoadhesive patches}

Patches were prepared by solvent casting method. Different polymer solutions were prepared according to composition shown in Table (1). All solutions were prepared using alkalinized water except for HPC (dissolved in alkalinized methanol) and chitosan (dissolved in $1.5 \% \mathrm{v} / \mathrm{v}$ glacial acetic acid). The prepared viscous solutions were left overnight at room temperature till becoming clear and bubblefree. Then they were casted into a glass Petri dish and allowed to dry in an oven maintained at $40^{\circ} \mathrm{C}$ till a flexible film was formed.

Patches containing lornoxicam were prepared by dissolving the calculated amount of the drug $(0.1 \% \mathrm{w} / \mathrm{v})$ in $25 \mathrm{ml}$ alkalinized distilled water $(5 \mathrm{ml}$ of $0.15 \mathrm{~N} \mathrm{NaOH} / 100 \mathrm{ml}$ water), alkalinized methanol $(5 \mathrm{ml}$ of $0.15 \mathrm{~N}$ $\mathrm{NaOH} / 100 \mathrm{ml}$ methanol), or $1.5 \% \mathrm{v} / \mathrm{v}$ glacial acetic acid. The drug solution was added to the polymer solution under stirring. Films were casted and then cut into patches with the desired dimensions. The samples were packed in aluminum foil and stored in a glass desiccator maintained at room temperature and $58 \%$ relative humidity; these conditions maintained the integrity and elasticity of the patches ${ }^{1}$.

\section{Evaluation of buccal patches \\ Determination of mass uniformity and patch thickness}

Determination of mass and thickness was done using three pieces of each patch, the thickness was measured using digital micrometer at different points of the patch, and the mass was measured by digital balance using pieces of $1 \mathrm{~cm}^{2}(1 \mathrm{~cm} \times 1 \mathrm{~cm})$. Data represented as mean $\pm S D(n=3)$. 
Table 1: Composition of lornoxicam buccal patches - forming solution.

\begin{tabular}{|c|lr||c|lc|}
\hline Formula & \multicolumn{2}{|c|}{ Composition (\%w/v) } & Formula & \multicolumn{2}{c|}{ Composition (\%w/v) } \\
\hline \multirow{5}{*}{ F1 } & Lornoxicam & 0.1 & & Lornoxicam & 0.1 \\
& Sod alginate & 4.0 & \multirow{2}{*}{ F6 } & PVA & 3.0 \\
& Glycerol & 5.0 & & Glycerol & 5.0 \\
& Alkalinized water & 100 & & Alkalinized water & 100 \\
\hline \multirow{5}{*}{ F2 } & Lornoxicam & 0.1 & & Lornoxicam & 0.1 \\
& Na CMC & 1.0 & \multirow{2}{*}{ F7 } & HPC & 10.0 \\
& Glycerol & 5.0 & & Glycerol & 5.0 \\
& Alkalinized water & 100 & & Alkalinized methanol & 100 \\
\hline \multirow{5}{*}{ F3 } & Lornoxicam & 0.1 & & Lornoxicam & 0.1 \\
& HEC & 1.0 & \multirow{2}{*}{ F8 } & HPMC & 4.0 \\
& Glycerol & 5.0 & & Glycerol & 5.0 \\
& Alkalinized water & 100 & & Alkalinized water & 100 \\
\hline \multirow{5}{*}{ F4 } & Lornoxicam & 0.1 & & Lornoxicam & 0.1 \\
& Gelatin & 5.0 & & HEC & 2.0 \\
& Glycerol & 5.0 & \multirow{2}{*}{ F9 } & HPMC & 2.0 \\
& Alkalinized water & 100 & & Glycerol & 5.0 \\
& & & & Alkalinized water & 100 \\
\hline \multirow{5}{*}{ F5 } & Lornoxicam & 0.1 & & Lornoxicam & 0.1 \\
& Chitosan & 1.5 & \multirow{2}{*}{ F10 } & HEC & 2.0 \\
& Glycerol & 5.0 & Gelatin & 2.0 \\
& Acetic acid (1.5\%) & 100 & & Glycerol & 5.0 \\
& & & & Alkalinized water & 100 \\
\hline \hline
\end{tabular}

Alkalinized water: $5 \mathrm{ml}$ of $0.15 \mathrm{~N} \mathrm{NaOH} / 100 \mathrm{ml}$ water.

Alkalinized methanol: $5 \mathrm{ml}$ of $0.15 \mathrm{~N} \mathrm{NaOH} / 100 \mathrm{ml}$ methanol.

\section{Determination of surface $\mathrm{pH}$}

The prepared buccal patches were left to swell for $2 \mathrm{hrs}$ on the surface of an agar plate, prepared by dissolving $2 \%(\mathrm{w} / \mathrm{v})$ agar in warmed phosphate buffer of $\mathrm{pH} 6.8$ under stirring and then pouring the solution into a Petri dish till gelling at room temperature ${ }^{4}$.

The surface $\mathrm{pH}$ was determined by $\mathrm{pH}$ paper placed on the surface of the swollen patch. The mean of three readings was recorded.

\section{Folding endurance test}

The folding endurance of each patch was determined by repeatedly folding the patch at the same place till it was broken or folded up to 300 times, which is considered satisfactory to reveal good film properties ${ }^{5}$.

\section{Determination of ex-vivo mucoadhesion time}

Ex-vivo mucoadhesion time was performed after the application of the films on freshly cut rabbit buccal mucosa. The rabbit buccal tissue was fixed on the internal side of a beaker with cyanoacrylate glue. Each film was cut to pieces of $1 \mathrm{~cm}^{2}$, one side of each film was moistened with $50 \mu 1$ of phosphate buffer $\mathrm{pH} 6.8$, then pasted to rabbit buccal mucosa by applying a light force with the finger tip. Then the beaker was filled with $200 \mathrm{ml}$ of phosphate buffer with $\mathrm{pH} 6.8$ and kept at $37^{\circ} \mathrm{C}$ for $2 \mathrm{~min}$. A $50 \mathrm{rpm}$ stirring was applied to simulate buccal cavity environment and adhesion time was evaluated for a period of $6 \mathrm{hrs}^{6}$. Each experiment was repeated three times and the mean value was calculated.

\section{In-vitro bioadhesion test}

The bioadhesive strength of different patches was measured using freshly cut rabbit buccal mucosa as a model mucosal membrane, the rabbit buccal mucosa was glued with cyanoacrylate adhesive on the ground surface of tissue holder made of plexiglass, the film was glued to another holder of the same size. The surface of the mucosal membrane was first blotted with a filter paper and then moistened with $25 \mu \mathrm{l}$ of phosphate buffer with $\mathrm{pH} 6.8$. 
The two holders with mucosal membrane and film were put in contact with each other with uniform and constant pressure for $5 \mathrm{~min}$ (preload time) to facilitate adhesion bonding. The tissue holder with buccal mucosa was allowed to hang on an iron stand with the help of a piece of aluminium wire, a prewieghed light weight polypropylene bag was attached to the hook on backside of the formulation holder with a piece of aluminium wire. Five minutes later, water was added to the polypropylene bag through an intravenous infusion set at a constant rate of $1 \mathrm{drop} / \mathrm{sec}$ until the film detached from the tissue. The water collected in the bag was measured and expressed as weight (g) required for detachment (bioadhesive strength). The average of three experiments was calculated.

Figure (1) shows a schematic presentation of the experiment design. The apparatus was assembled in our laboratory and a modification of the apparatus was previously applied by Parodi et al. ${ }^{7}$.

Force of adhesion and bond strength for each patch were calculated according to the following equations:

Force of adhesion $(\mathrm{N})=$

bioadhesive strength $\times 9.81 / 1000$

Bond strength $\left(\mathrm{N} \mathrm{m}^{-2}\right)=$ force of adhesion/disk surface area

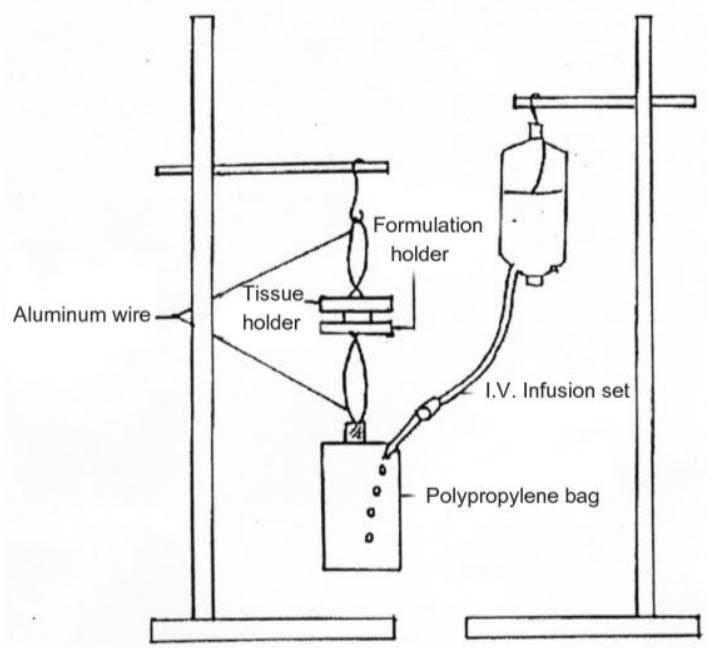

Fig. 1: Modified apparatus for in-vitro bioadhesion test.

\section{Swelling study}

Film swelling properties were evaluated by determining the percentage of hydration (or swelling index). Three pieces (of $5 \mathrm{~cm}^{2}$ ) of each patch were used. The original patch weight was determined $\left(\mathrm{W}_{1}\right)$, then the patch was allowed to swell over agar plate (2\% agar was dissolved in warmed phosphate buffer of $\mathrm{pH} 6.8$ and left to form gel) for predetermined periods of time $(5,10,15,30,45,60,90 \mathrm{~min})$. The swollen patches were wiped off from excess surface water using filter paper and reweighed $\left(\mathrm{W}_{2}\right)^{8}$. Each experiment was performed in triplicate. Percentage of hydration (swelling index) was calculated using the following equation:

$\%$ of hydration $($ swelling index $)=\left(\mathrm{W}_{2}-\mathrm{W}_{1}\right) / \mathrm{W}_{1} \times 100$

\section{Drug content}

An area of $5 \mathrm{~cm}^{2}(5 \mathrm{~cm} \times 1 \mathrm{~cm})$ of each patch was dissolved in $100 \mathrm{ml}$ phosphate buffer of $\mathrm{pH}$ 6.8. A 5 ml-sample was taken and assayed spectrophotometrically at $377 \mathrm{~nm}$ and the drug content was calculated. Drug-free patches of the same dimensions were used as blank. Each experiment was done in triplicate, mean and SD were calculated.

\section{In-vitro release of lornoxicam from the prepared formulations}

The ERWEKA dissolution apparatus was used to study the drug release from buccal patches, the dissolution medium was $200 \mathrm{ml}$ of phosphate buffer with $\mathrm{pH} 6.8$. The release was performed at $37 \pm 0.5^{\circ} \mathrm{C}$ at a rotation speed of 50 rpm. One side of the buccal patch (of $5 \mathrm{~cm}^{2}$ ) was attached to a glass disk with instant adhesive (cyanoacrylate); the disk was put in the bottom of the dissolution vessel so that the patch remained on the upper side of the disk ${ }^{9}$. Samples of $5 \mathrm{ml}$ were withdrawn at predetermined time intervals (for up to $6 \mathrm{hrs}$ ) and replaced with fresh medium; the samples were filtered and assayed spectrophotometrically at $377 \mathrm{~nm}$.

\section{In-vitro buccal permeation study}

The in-vitro study of lornoxicam permeation through the rabbit buccal mucosa was performed using a glass diffusion cell at $37 \pm 0.2^{\circ} \mathrm{C}$. Rabbit buccal mucosa was obtained from a local slaughterhouse (used within $2 \mathrm{hrs}$ of slaughter). Freshly obtained rabbit buccal mucosa was mounted between the donor and receptor compartments of Franz diffusion cell so that the smooth surface of the mucosa faced the donor compartment. This experiment was 
conducted using patches selected according to previous experimental results. The patch was placed on the mucosa and the compartments were clamped together. The donor compartment was filled with $3 \mathrm{ml}$ of phosphate buffer with $\mathrm{pH}$ 6.8. The receptor compartment (5 ml capacity) was filled with phosphate buffer of $\mathrm{pH} 6.8$ and the hydrodynamics in the receptor compartment was maintained by stirring with a magnetic bead at $100 \mathrm{rpm}^{10}$. One $\mathrm{ml}$ samples were withdrawn at predetermined time intervals (for up to $24 \mathrm{hrs}$ ) and assayed spectrophotometrically at $377 \mathrm{~nm}$. Effect of incorporation of permeation enhancers $(3 \% \mathrm{w} / \mathrm{v}$ sodium tauroglycocholate or $30 \% \mathrm{w} / \mathrm{v}$ propylene glycol) on the drug's permeation was also evaluated. Some patches showed cracking or lost consistency when the enhancer was incorporated and were excluded from this part.

\section{Kinetic analysis of drug release data}

The in-vitro release profiles were tested for their kinetic behavior in order to establish the kind of mechanism possibly involved in lornoxicam release from the patch matrix. Data were analyzed according to zero order, first order and Higuchi diffusion models.

\section{RESULTS AND DISCUSSION}

\section{Mass uniformity and patch thickness}

All the patches $(1 \mathrm{~cm} \times 1 \mathrm{~cm})$ showed a uniform mass and thickness as indicated by the SD values in Table (2), patches masses ranged from 0.243 to $0.594 \mathrm{~g}$ and thickness ranged from 0.033 to $0.09 \mathrm{~cm}$.

\section{Surface pH}

The surface $\mathrm{pH}$ of all formulations was within 9.0 to 9.5 (since they were prepared in alkalinized vehicles). Except for F5 the surface $\mathrm{pH}$ was 5.5 (as it was prepared in $1.5 \% \mathrm{v} / \mathrm{v}$ glacial acetic acid). Hence no or minimal reversible mucosal irritation was expected.

\section{Folding endurance}

The recorded folding endurance of all patches was >300 times, which is considered satisfactory to reveal good film properties.

\section{Ex-vivo mucoadhesion time}

Mucoadhesion time of different polymeric patches is shown in Table (3). HPC patch (F7) and the mixed polymer patches of HEC with either HPMC (F9), or gelatin (F10) showed high adhesion time (more than four hours). HPMC patch (F8) and HEC patch (F3) showed moderate adhesion time (three hours) but chitosan (F5) and PVA (F6) patches showed very low adhesion time (less than six minutes). This difference depends upon several factors that affect the effectiveness of such formulations. First of all, solubility in water and hydration, polymers of high water solubility are less effective as mucoadhesive polymers (such as Na CMC). The polymer that tends to retain its structure (such as HPC, HEC, and HPMC) has a higher adhesion time? Another important factor to be considered is the homogeneity of the polymer solution mixtures ${ }^{9}$.

Table 2: Mass uniformity and patch thickness.

\begin{tabular}{|c|c|c|}
\hline Formula & $\begin{array}{c}\text { Mean patch mass } \\
(\mathrm{g}) \pm \mathrm{SD}\end{array}$ & $\begin{array}{c}\text { Mean patch thickness } \\
(\mathrm{cm}) \pm \mathrm{SD}\end{array}$ \\
\hline F1 & $0.440 \pm 0.014$ & $0.090 \pm 0.003$ \\
F2 & $0.243 \pm 0.026$ & $0.033 \pm 0.006$ \\
F3 & $0.266 \pm 0.016$ & $0.047 \pm 0.006$ \\
F4 & $0.376 \pm 0.034$ & $0.077 \pm 0.006$ \\
F5 & $0.253 \pm 0.020$ & $0.047 \pm 0.012$ \\
F6 & $0.379 \pm 0.022$ & $0.057 \pm 0.006$ \\
F7 & $0.594 \pm 0.015$ & $0.100 \pm 0.005$ \\
F8 & $0.362 \pm 0.010$ & $0.080 \pm 0.003$ \\
F9 & $0.328 \pm 0.025$ & $0.060 \pm 0.004$ \\
F10 & $0.336 \pm 0.001$ & $0.077 \pm 0.006$ \\
\hline
\end{tabular}

Surface area of weighed patches: $1 \mathrm{~cm}^{2}(1 \mathrm{~cm} \times 1 \mathrm{~cm})$. 
Table 3: Bioadhesive parameters for different patches.

\begin{tabular}{|c|c|c|c|c||}
\hline Formula & $\begin{array}{c}\text { Mean adhesion time } \\
(\min ) \pm \mathrm{SD}\end{array}$ & $\begin{array}{c}\text { Mean bioadhesive strength } \\
(\mathrm{g}) \pm \mathrm{SD}\end{array}$ & $\begin{array}{c}\text { Force of adhesion } \\
(\mathrm{N})\end{array}$ & $\begin{array}{c}\text { Bond strength } \\
\left(\mathrm{N} \mathrm{m}^{-2}\right)\end{array}$ \\
\hline F1 & $55 \pm 5$ & $63.4 \pm 1.5$ & 0.622 & 6219.54 \\
F2 & $52 \pm 2$ & $98.6 \pm 5.2$ & 0.968 & 9676.58 \\
F3 & $195 \pm 10$ & $100 \pm 1.8$ & 0.981 & 9810.00 \\
F4 & $25 \pm 2$ & $95.5 \pm 2.6$ & 0.936 & 9363.65 \\
F5 & $1 \pm 0.5$ & $40.5 \pm 4.5$ & 0.398 & 3976.97 \\
F6 & $0.5 \pm 0.25$ & $3 \pm 0.6$ & 0.029 & 294.30 \\
F7 & $270 \pm 7$ & $75.5 \pm 3.4$ & 0.740 & 7402.63 \\
F8 & $180 \pm 4$ & $53.7 \pm 5.7$ & 0.527 & 5267.97 \\
F9 & $>360$ & $120 \pm 4.9$ & 1.177 & 11772.00 \\
F10 & $>360$ & $130.5 \pm 2.8$ & 1.280 & 12804.01 \\
\hline
\end{tabular}

\section{In-vitro bioadhesion}

HEC (F3), Na CMC (F2), gelatin (F4) and the mixed polymer patches (F9, F10) showed high bioadhesive strength $(\geq 100 \mathrm{~g})$, but HPMC (F8), HPC (F7) and chitosan (F5) patches showed moderate bioadhesive strength while PVA patch (F6) showed very weak bioadhesive strength (Table 3).

No correlation was found between the bioadhesion force and the residence time of the polymers. It seems that highly bioadhesive polymers do not necessarily reside longer on the mucosal surface. Surface charge density and chain flexibility are considered to be prerequisites for bioadhesion, whereas the residence time is primarily dependent on the dissolution rate of the polymer?

\section{Swelling study}

Swelling of polymer matrix depends very much on the rate of penetrant entry into the matrix. The penetrant uptake measurement has been used primarily for evaluating the effect of polymer-penetrant interaction that enables the release of drug to take place at a constant rate $^{11}$. Swelling study was done for a period of $1.5 \mathrm{hrs}$ because after this time the patches became sticky and very difficult to be weighed. Some formulations showed erosion before this time and could not be weighed (F2, F3 and F4 as shown in Fig. 2). HEC patch (F3) and Na CMC patch (F2) showed a high swelling index (320\% and 300\%, respectively). Sodium alginate patch (F1) and mixed polymer patch of HEC and HPMC (F9) showed moderate swelling index (165\% and $101 \%$, respectively), while HPC patch (F7), chitosan patch (F5) and
PVA patch (F6) showed the lowest swelling index $(22 \%, 53 \%$ and $8 \%$, respectively). Swelling index values are represented in Figure (2).
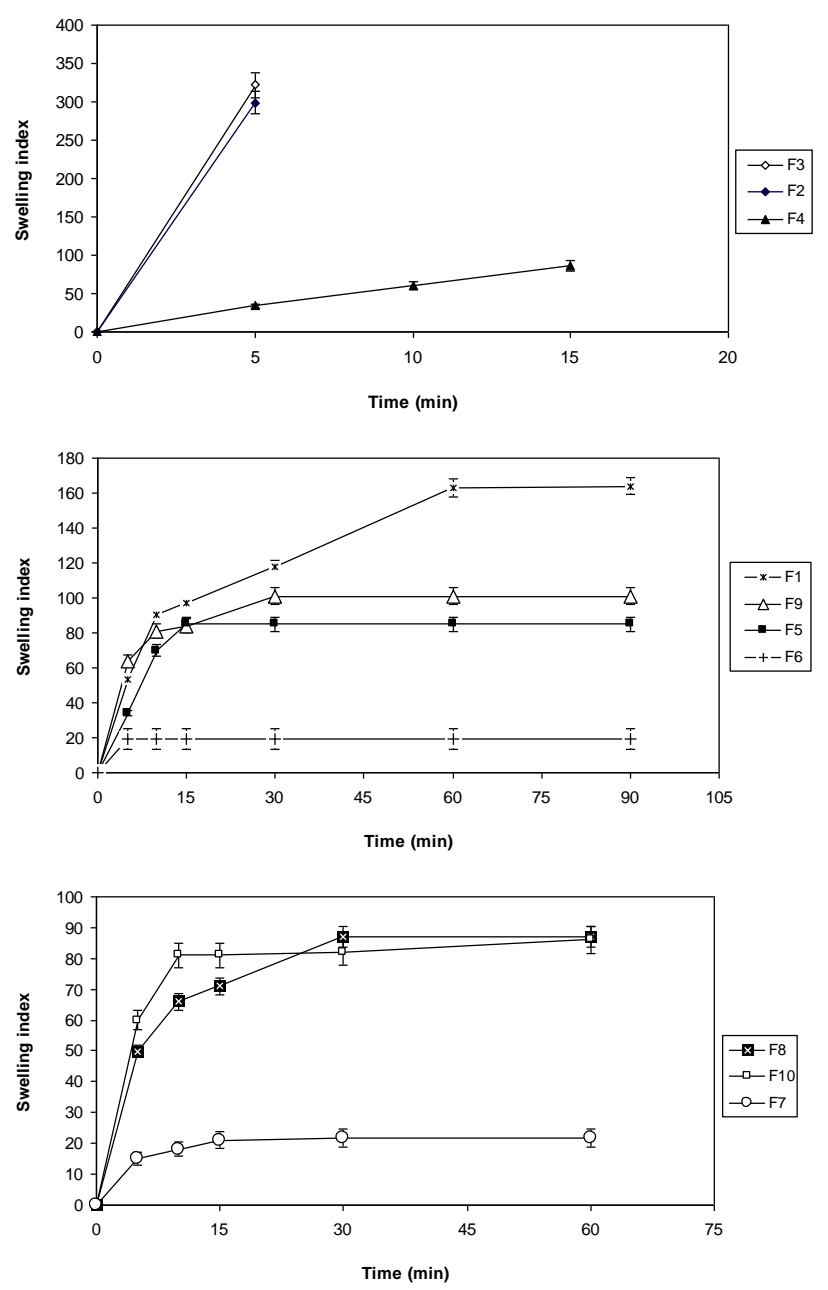

Fig. 2: Swelling index of different lornoxicam buccal patches. 
The low swelling index calculated for chitosan may be attributed to its poor solubility in water ${ }^{5}$. Differences in swelling of the tested hydrophilic polymers could be explained by the difference in resistance of the matrix network structure (hydrogen bond) to the movement of water molecules ${ }^{12}$.

The hydration rate of polymers depends on the nature of the substituent present and the degree of substitution. Also, the hydrophilicity of cellulose ethers increases with a decrease in the alkyl chain length. Thus it is not surprising that HEC exhibited a considerably higher degree of hydration and water uptake as compared to HPC.

\section{Drug content}

Estimation of drug content at different places on each patch indicated that lornoxicam was distributed uniformly throughout the patches. The drug content of all patches ranged from $98.2 \%$ to $100.5 \%$ of the claimed drug content (Table 4). Each patch of dimensions $(5 \mathrm{~cm} \times 1 \mathrm{~cm})$ contains $3.9 \mathrm{mg} \pm 0.08 \mathrm{mg}$ of lornoxicam.

Table 4: Drug content of different buccal patches of $5 \mathrm{~cm}^{2}$ surface area.

\begin{tabular}{|c|c|c|}
\hline Formula & $\begin{array}{c}\text { Drug content } \\
(\mathrm{mg})\end{array}$ & $\begin{array}{c}\text { \% of claimed } \\
\text { drug content }\end{array}$ \\
\hline F1 & $3.97 \pm 0.01$ & $99.18 \pm 0.35$ \\
F2 & $4.01 \pm 0.05$ & $100.18 \pm 1.35$ \\
F3 & $3.97 \pm 0.01$ & $99.18 \pm 0.35$ \\
F4 & $4.01 \pm 0.16$ & $100.18 \pm 4.12$ \\
F5 & $4.01 \pm 0.01$ & $100.18 \pm 0.33$ \\
F6 & $4.00 \pm 0.13$ & $100 \pm 3.35$ \\
F7 & $4.01 \pm 0.05$ & $100.18 \pm 1.30$ \\
F8 & $4.01 \pm 0.17$ & $100.18 \pm 4.35$ \\
F9 & $3.93 \pm 0.05$ & $98.18 \pm 1.35$ \\
F10 & $4.02 \pm 0.06$ & $100.50 \pm 1.47$ \\
\hline
\end{tabular}

Claimed drug content: $4 \mathrm{mg} / 5 \mathrm{~cm}^{2}$ patch.

\section{In-vitro release of lornoxicam from the prepared buccal patches}

The drug release profiles from different patches are shown in Figure (3). Gelatin (F4), $\mathrm{Na}$ CMC (F2), PVA (F6) and sodium alginate (F1) patches showed a fairly fast drug release, after four hours all the amount of incorporated drug was released. HPMC (F8) and chitosan (F5) patches showed a moderate release, after six hours more than $80 \%$ of loaded drug was released. HEC (F3), HPC (F7) patches and the mixed polymer patch of HEC and gelatin (F10) showed sustained release, after six hours $\leq 75 \%$ of loaded drug was released. The mixed polymer patches of either gelatin or HPMC with HEC (F10 and F9, respectively) showed slower release than the patches prepared with gelatin or HPMC alone.
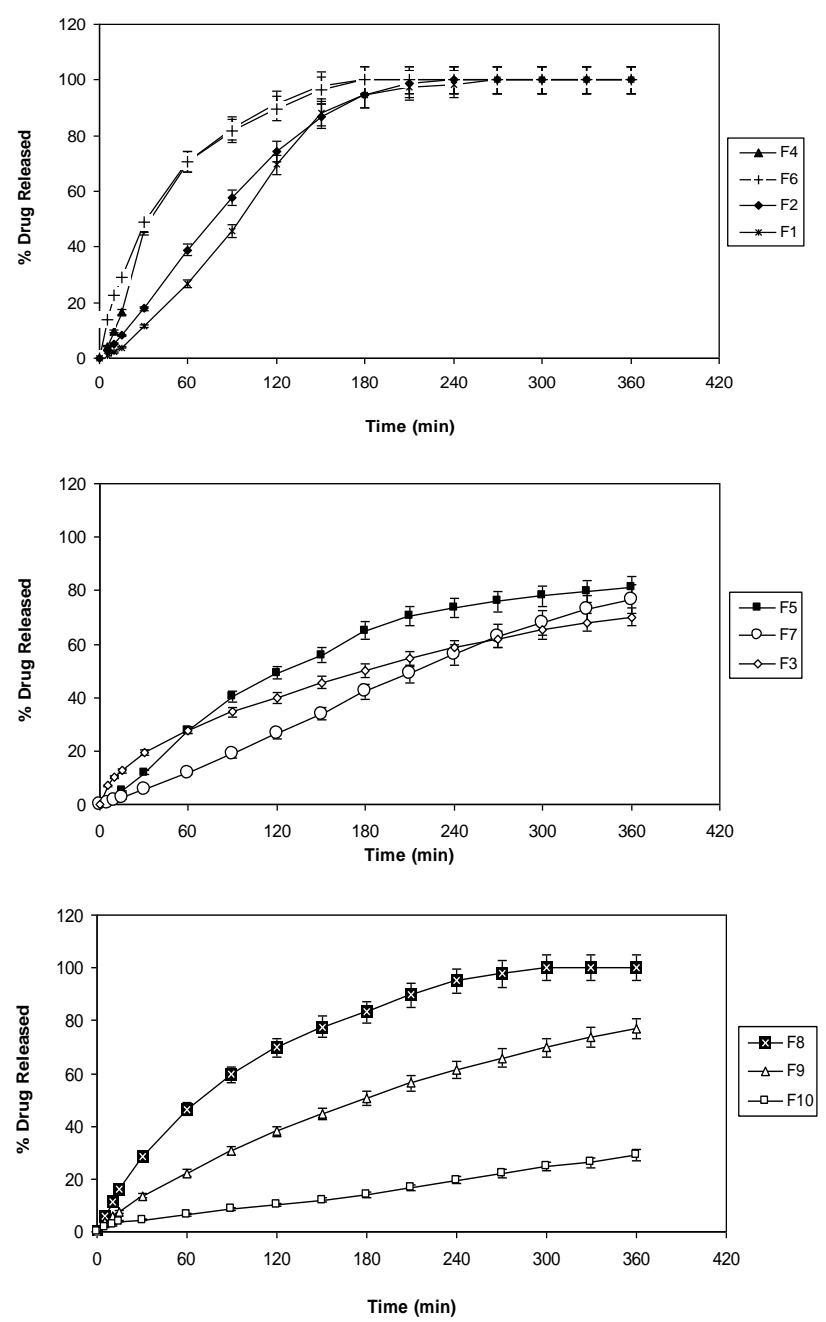

Fig. 3: Release of lornoxicam from different buccal patches.

Marked differences in the lornoxicam release patterns were observed between PVA patch and the patches formulated of cellulose derivatives. During dissolution, PVA swelled forming a gel layer on the exposed patch surfaces. The loosely bound polymer molecules were easily eroded; allowing the release of lornoxicam in a higher rate compared to the patches prepared using cellulosic derivatives ${ }^{13}$. In addition, the relatively high swelling of HEC 
increased the gel layer thickness and consequently the diffusion path length, which in turn may be the cause of the slower drug release from HEC patches compared to PVA, gelatin, and sodium alginate patches.

$\mathrm{Na} \mathrm{CMC}$ is characterized by a higher dissolution rate compared to HPMC, so that a slower release of the drug from F8 compared to F2 was observed.

The higher release of lornoxicam from gelatin (F4), Na CMC (F2), PVA (F6), and sodium alginate $(\mathrm{F} 1)$ patches can also be explained by the viscosity of the polymer solutions; a preliminary study showed that a solution of gelatin, $\mathrm{Na}$ CMC, PVA or sodium alginate had lower viscosity than a solution of HEC, HPC, HPMC or chitosan. As the viscosity is related to the strength and durability of the gel layer, the diffusion of the drug will be easier in case of F4, F2, F6 and F1 patches.

\section{Kinetic analysis of drug release data}

Mathematical treatment of the release data of lornoxicam from different formulations indicated that, the release patterns were zero order for F1, F7 and F10 and Higuchi diffusion for F2, F3, F4, F5, F6, F8 and F9. These results are shown in Table (5). The Higuchi's model was appropriate to describe lornoxicam release behavior. This kind of mechanism is in agreement with swellable systems in which drug release is more affected by the liquid penetration rate than by the relaxation rate of the polymeric chains. These results can be explained by the very low film thickness that characterizes these film matrices. In this case, this particular patch geometry permits the hydration to prevail over the relaxation rate of the polymeric chains ${ }^{12 \& 13}$

\section{In-vitro buccal permeation study}

Figure (4) shows the permeation profiles of lornoxicam from different buccal patches. F4 and F5 showed higher mucosal permeation when compared to other formulations. In general, formulations with propylene glycol used as an enhancer (Fig. 4b) showed higher mucosal penetration of the drug when compared with the same formulations with sodium tauroglycolate used as an enhancer (Fig. 4c). Table (6) shows the permeation parameters in presence and absence of permeation enhancers. It is likely that the coapplication of bile salts to the buccal epithelium provokes lipid solubilization, both in the intercellular domains and from the cell membranes. The solubilization of lipids in the intercellular space might increase the diffusivity of the drug studied and thus enhances their overall transport rate. In addition, the solubilization of phospholipids from the cell membranes might facilitate transport to the cytoplasm ${ }^{14}$. The main effect of propylene glycol appears to involve a solventdrag effect; it improves the solubility of drugs (lornoxicam is completely insoluble in water) resulting in increased drug partitioning into the buccal mucosa. This solvent-drag effect may have been responsible for the enhanced lornoxicam permeation ${ }^{15}$. This mechanism can show effect in the in-vitro study, which may explain the better results obtained by propylene glycol compared to the bile salt.

Table 5: Kinetic parameters of the release data of lornoxicam from buccal patches.

\begin{tabular}{|c|c|c|c|c|c|c|c||}
\hline \multirow{2}{*}{ Formula } & \multicolumn{2}{|c|}{ Zero } & \multicolumn{2}{c|}{ First } & \multicolumn{2}{c|}{ Diffusion } & \multirow{2}{*}{$\begin{array}{c}\text { Order of } \\
\text { release }\end{array}$} \\
\cline { 2 - 7 } & $\mathrm{R}$ & $\mathrm{K}$ & $\mathrm{R}$ & $\mathrm{K}$ & $\mathrm{R}$ & $\mathrm{K}$ & Zero \\
\hline F1 & 0.979 & 0.480 & -0.606 & -0.013 & 0.971 & 7.823 & Diffusion \\
\hline F2 & 0.976 & 0.465 & -0.694 & -0.022 & 0.985 & 7.734 & Diffusion \\
\hline F3 & 0.972 & 0.184 & -0.038 & -0.0003 & 0.100 & 3.822 & Diffusion \\
\hline F4 & 0.900 & 0.436 & -0.829 & -0.024 & 0.967 & 7.710 & Diffusion \\
\hline F5 & 0.956 & 0.245 & -0.235 & -0.002 & 0.989 & 5.117 & Diffion \\
\hline F6 & 0.905 & 0.397 & -0.800 & -0.021 & 0.978 & 7.051 & Diffusion \\
\hline F7 & 0.998 & 0.226 & -0.118 & -0.001 & 0.972 & 4.443 & Zero \\
\hline F8 & 0.937 & 0.282 & -0.800 & -0.016 & 0.989 & 6.003 & Diffusion \\
\hline F9 & 0.989 & 0.215 & -0.122 & -0.001 & 0.994 & 4.381 & Diffusion \\
\hline F10 & 0.997 & 0.075 & 0.227 & 0.002 & 0.970 & 1.481 & Zero \\
\hline \hline
\end{tabular}


(a)

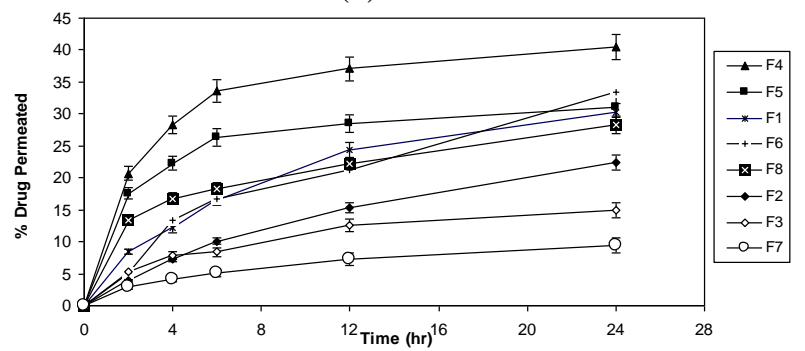

(b)

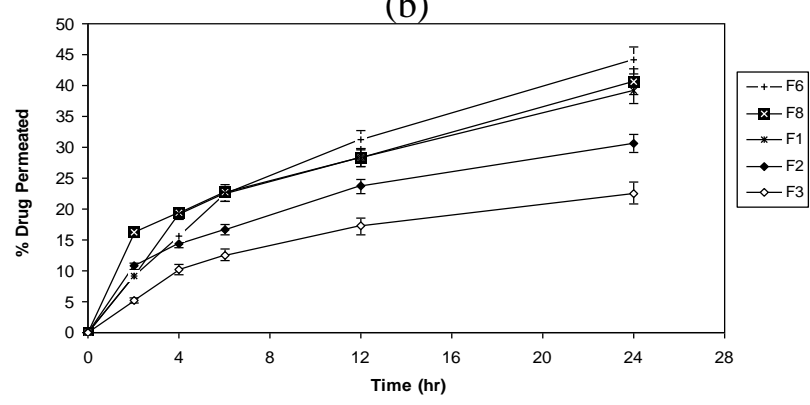

(c)

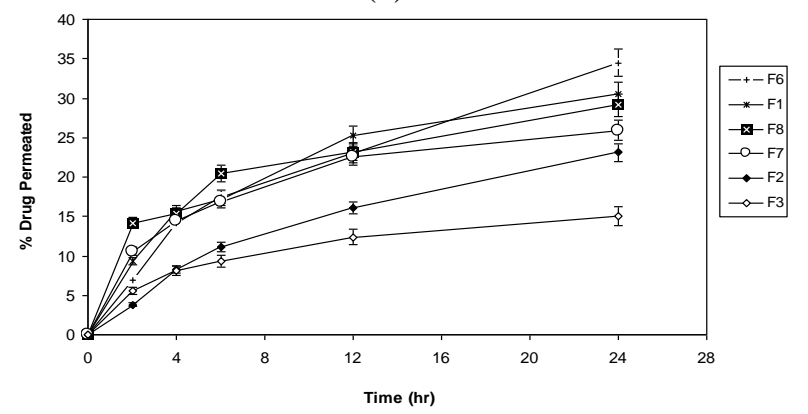

Fig. 4: In-vitro permeation of lornoxicam from different buccal patches. (a): patches containing no enhancer, (b): patches containing 30\% w/v Propylene glycol as an enhancer, and (c): patches containing 3\% w/v Sodium tauroglycolate as an enhancer. Patches which cracked upon addition of enhancer were excluded.

Table 6: In-vitro skin permeation parameters of lornoxicam incorporated in different buccal patches.

\begin{tabular}{|c|c|c|c|}
\hline \multirow{2}{*}{ Formula } & \multirow{2}{*}{ Enhancer } & \multicolumn{2}{|c|}{ Permeation parameters } \\
\cline { 2 - 4 } & - & $\mathrm{J}\left(\mathrm{ug} \mathrm{cm}^{2} \mathrm{hr}^{-1}\right)$ & $\mathrm{P} \mathrm{x} \mathrm{10}\left(\mathrm{cm} \mathrm{hr}^{-1}\right)$ \\
\hline \multirow{3}{*}{ F1 } & - & 19.98 & 199.8 \\
\cline { 2 - 4 } & $3 \%$ Sod. tauroglycolate & 22.23 & 222.30 \\
\cline { 2 - 4 } & $30 \%$ propylene glycol & 25.63 & 256.35 \\
\hline \multirow{4}{*}{ F2 } & - & 11.53 & 115.37 \\
\cline { 2 - 4 } & $3 \%$ Sod. tauroglycolate & 12.19 & 121.93 \\
\cline { 2 - 4 } & $30 \%$ propylene glycol & 22.55 & 225.5 \\
\hline \multirow{3}{*}{ F3 } & - & 11.58 & 115.81 \\
\cline { 2 - 4 } & $3 \%$ Sod. tauroglycolate & 12.06 & 120.56 \\
\cline { 2 - 4 } & $30 \%$ propylene glycol & 14.55 & 145.5 \\
\hline F4 & - & 41.70 & 417.06 \\
\hline F5 & - & 33.56 & 335.62 \\
\hline \multirow{3}{*}{ F6 } & - & 17.77 & 177.75 \\
\cline { 2 - 4 } & $3 \%$ Sod. tauroglycolate & 19.90 & 199.06 \\
\cline { 2 - 4 } & $30 \%$ propylene glycol & 24.96 & 249.68 \\
\hline \multirow{3}{*}{ F7 } & - & 6.57 & 65.77 \\
\cline { 2 - 4 } & $3 \%$ Sod. tauroglycolate & 22.05 & 220.56 \\
\hline \multirow{3}{*}{ F8 } & - & 25.36 & 253.66 \\
\cline { 2 - 4 } & $3 \%$ Sod. tauroglycolate & 26.21 & 262.13 \\
\cline { 2 - 4 } & $30 \%$ propylene glycol & 31.19 & 311.97 \\
\hline
\end{tabular}

N.B. Patches which cracked upon addition of the enhancer were excluded from the study of permeation enhancers effect. 


\section{Conclusion}

Lornoxicam has been successfully prepared in various mucoadhesive buccal patches; using different polymers such as sodium alginate, Na CMC, HPC, HPMC, PVA, gelatin, chitosan and HEC in different concentrations.

The formulated patches had good appearance and physical characteristics (no cracks, uniform thickness, mass and drug content) and showed high bioahesion characteristics.

Gelatin, Sodium alginate and $\mathrm{Na} \mathrm{CMC}$ patches showed the highest drug release rate of the drug in-vitro and more drug permeation through rabbit buccal mucosa than other formulations. The obtained results suggested that the formulations can be promising therapeutic systems for the buccal delivery of lornoxicam to avoid the disadvantages of parenteral and oral routes.

The in-vitro study is considered a useful methodology for screening lornoxicam buccal patches formulations to be considered for further studies such as clinical evaluation.

\section{REFERENCES}

1- N. A. Nafee, F. A. Ismail, N. A. Boraei and L.M. Mortada, Int. J. Pharm., 264, 1 (2003).

2- Z. Yifan, Z. Dafang, S. Dayong, G. Yingjie, C. Xiaoyan and Z. Hui, Br. J. Clin. Pharmacol., 59, 14 (2005).

3- S. Radhofer - Welte, P. dittrich, M. Simin and P.E. Branebjerg, Clin. Drug Invest., 28, 345 (2008).
4- N. A. Nafee, N. A. Boraei, F.A. Ismail and L.M. Mortada, Acta Pharm., 53, 199 (2003).

5- C-M. Lehr, J. A. Bouwstra, E. H. Schacht and H. E. Junginger, Int. J. Pharm., 7843 (1992).

6- F. Nakamura, R. Ohta, Y. Machida and T. Nagai, ibid., 134, 173 (1996).

7- B. Parodi, E. Russo, G. Caviglioli, S. Cafaggi and G. Bignardi, Drug Dev. Ind. Pharm., 22, 445 (1996).

8- K. K. Peh and C. F. Wong, J. Pharm. Pharmaceut. Sci., 2, 53 (1999).

9- L. Perioli, V. Ambrogi, F. Angelici, M. Ricci, S. Giovagnoli, M. Capuccella and C. Rossi, J. Controlled Release, 99, 73 (2004).

10- M. S. El-Samaligy, S.A. Yahia and E. B. Basalious, Int. J. Pharm., 286 (2004).

11- T. K. Mandal and L. A., Bostanian, Pharm. Dev. Technol., 5, 555 (2000).

12- S. P. Panomsuk, T. Hatanaka, T. Aiba, K. Katayama and T. Koizumi, Chem. Pharm. Bull., 44, 1039 (1996).

13- R. W. Korsmeyer, R. Gurny, E. Doelker, P. Buri, and N. A. Peppas, Int. J. Pharm., 15, 25 (1983).

14- A. J. Hoogstraate, S. Senel, C. Cullander, J. Verhoef, H. E. Junginger and H. E. Bodde, J. Controlled Release, 40, 211 (1996).

15- B. W. Barry and S. L. Bennett, J. Pharm. Pharmacol., 39, 535 (1987). 